\title{
Chapter 5 \\ Understanding the Role of Soils and Management on Crops in the Face of Climate Uncertainty in Zimbabwe: A Sensitivity Analysis
}

\author{
Patricia Masikati, Katrien Descheemaeker, and Olivier Crespo
}

\subsection{Introduction}

More than $50 \%$ of agricultural land in Africa is degraded and yields of the main staple crops have been at the lower end of the global range for decades (UNCCD 2014; Folberth et al. 2013). To meet the demands of a growing population, agricultural land has expanded into forests. This, coupled with unsustainable agricultural practices has led to increased land degradation (Lisk 2009; GGCA 2012). Africa is one of the most vulnerable continents because of its highly sensitive social and ecological systems and its limited institutional and economic capacity to respond appropriately to these emerging threats (Lisk 2009; GGCA 2012; Perez et al. 2015). Although climate change affects a number of development sectors, the risk to agriculture stands out since the sector represents a significant part of the economies of many African countries (Vermeulen et al. 2012). There is no doubt that climate change will amplify drivers of land degradation and pose increased threats on smallholders' livelihoods of which the majority are women (GGCA 2012; UNCCD 2014).

Degradation of agricultural land is causing annual yield reductions of $0.5-1 \%$ suggesting productivity loss of at least $20 \%$ in the next 40 years. In addition, climate

\footnotetext{
P. Masikati $(\bowtie)$

World Agroforestry Center (ICRAF), Lusaka, Zambia

e-mail: P.Masikati@cgiar.org

K. Descheemaeker

Plant Production Systems, Wageningen University, Wageningen, the Netherlands

O. Crespo

Climate System Analysis Group, University of Cape Town, Rondebosch, South Africa
} 
change impacts are projected to reduce yields by up to 25\% (Ioras et al. 2014; Asseng et al. 2015; Rurinda et al. 2015). Agriculture-based livelihood systems that are already vulnerable to food insecurity will face immediate risk if such yield reductions would occur. Although there has been progress made to understand the impact of climate change and variability on different crops in Africa, there is limited knowledge on how crop-soil systems respond to climate change. Characteristics of different soils vary; for example, clay soils with high organic matter have low thermal conductivity as well as high water holding capacity (Makinen et al. 2017). In contrast, sandy soils, which are predominant in smallholder farming systems, have high thermal conductivity and low water holding capacity (Moyo 2001; Nyamangara et al. 2001). However, the levels of fertility of sandy soils within and across farms greatly depend on the soil-fertility management practices used (Tittonell et al. 2007; Zingore et al. 2011). Soil-climate combination also plays a key role. The magnitude of crop responses to climate is highly sensitive to the soil type (Folberth et al. 2016; Makinen et al. 2017). Farmers in Nkayi, Zimbabwe, have already experienced this; during years of above-average rainfall, farming on clay soils generated a better harvest than on sandy soils, while the reverse is also true.

Empirical and quantitative information regarding the dependency of yield responses to agro-climatic variables on soil type is needed for designing effective climate-smart adaptation methods and enhancing the resilience of smallholder farming systems in the region (Piikki et al. 2015; Folberth et al. 2016; Makinen et al. 2017). Crop models are important tools that can be used to unravel the importance of soil type on crop responses to climate change and variability. However, model choice is also important as different model configurations, operation time steps, physiobiological processes, and others determine the model outputs (Asseng et al. 2015). Here we use the Decision Support System For Agrotechnology Transfer (DSSAT) model and the Agricultural Production Systems Simulator (APSIM) model (McCown et al. 1996; Jones et al. 2003; Hoogenboom et al. 2010; Holzworth et al. 2015). The two models simulate the dynamics of phenological development, biomass growth and partitioning, water and nitrogen cycling in an atmosphere-cropsoil system driven by daily weather variables that include rainfall, maximum and minimum temperatures and solar radiation (Hoogenboom et al. 2010; Holzworth et al. 2015). We use the two models to (1) assess the sensitivity of maize and groundnuts to individual climatic factors such as rainfall, temperature and $\mathrm{CO}_{2}$ concentration, under three soil types differentiated by levels of organic carbon and plant available soil water (2) simulate the combined impacts of future climate (2040 2070) on the two crops across the three soil types. Both soil fertility and climate are important issues in smallholder farming systems and will have different impacts on plant production and crop yields under future climate change. Production may increase or decrease depending on plant response to the interactions between climate and soil type, hence the importance to assess these impacts to inform adaptation decision-making. 


\subsection{Methods}

\subsubsection{Study Site}

Nkayi district is located in the northwestern part of Zimbabwe. Soils in the area are predominantly sandy. Soil organic carbon varies between $0.4 \%$ and $0.8 \%$ in the top layers while the water holding capacity varies from 52 to $102 \mathrm{~mm}$ (Moyo 2001). Maize is the major staple cereal while groundnuts are generally considered women crops that can improve both household income and nutrition. Groundnut is a multipurpose crop that can be used to improve soil fertility as well as the quality of livestock feed, especially during the dry season. Nkayi has a short growing season and limited water availability. Yields are not necessarily linked with higher nitrogen input due to interactions between nitrogen-induced growth and its effects on water use and water availability at different growth stages, especially during grain filling.

Historical changes in climate in the district show increasing temperature trends and recent projections show increases of approximately $1-2{ }^{\circ} \mathrm{C}$ in the near future, 2-3 ${ }^{\circ} \mathrm{C}$ in the mid-century, $2-5{ }^{\circ} \mathrm{C}$ by end of century (Masikati et al. 2015). Projections (medium confidence) show that rainfall change direction and amplitude are uncertain, yet averages would remain within or close to baseline variability. Seasonality seems to remain unchanged with possible rainfall reduction at the beginning of the rainy season (Masikati et al. 2015). These projected changes will have different impacts on plant production and crop yields as production may increase or decrease depending on the interactions between crops, climate $\left(\mathrm{CO}_{2}\right.$, temperature and rainfall) and soil type.

\subsubsection{Climate Data}

The best available historical weather record was gap-filled with AgMERRA data to create a 30 yearlong daily climate data set for Nkayi district (Ruane et al. 2014). To assess sensitivity of maize and groundnuts to different climatic factors; temperature (minimum and maximum, $\mathrm{CO}_{2}$ and rainfall) we used increments as shown in Table 5.1. To assess the second objective, we use two climate scenarios generated under two Representative Concentration Pathways (RCP), RCP4.5 and RCP8.5 for mid-century (2040-2070) (Ruane and McDermid 2017) (Fig. 5.1a, b) The two

Table 5.1 Factors and levels considered for sensitivity analyses

\begin{tabular}{l|l}
\hline Sensitivity analyses & \\
\hline $\mathrm{CO}_{2}(\mathrm{ppm})$ & $360,450,540,630,720($ with 0 and $60 \mathrm{~kg} \mathrm{~N} / \mathrm{ha})$ \\
\hline Temperature $\left({ }^{\circ} \mathrm{C}\right)$ & $-2,0,2,4,6,8$ \\
\hline Rain $(\%$ change $)$ & $0.25,0.5,0.75,1,1.25,1.5,1.75,2$ \\
\hline Fertilizer response $(\mathrm{kg} / \mathrm{ha})$ & $0,30,60,90,120,150,180$ \\
\hline
\end{tabular}



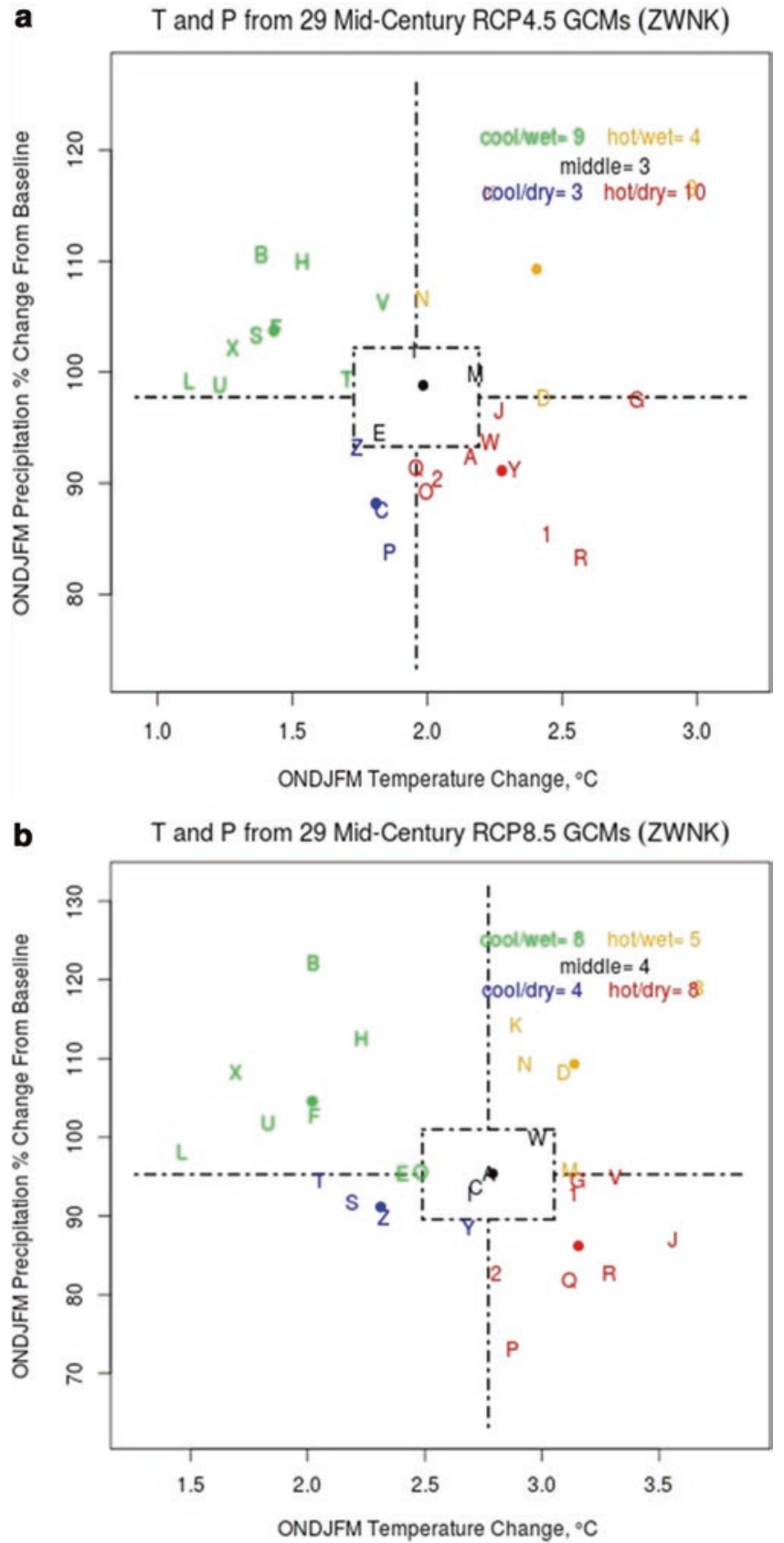

Fig. 5.1 (a) Mid-century temperature and precipitation changes in Nkayi, Zimbabwe, from 29 General Circulation Models (GCMs) under RCP4.5 and RCP 8.5 (b) Sub-setting of (GCMs) represented by different letters with different colored dots showing average changes in precipitation and temperature as predicted by GCMs showing projected cool/wet, cool/dry, hot/wet, hot/dry and middle conditions 
selected were the hot/wet and hot/dry scenarios in view of likely increases of temperature while rainfall change direction is uncertain.

\subsubsection{Crop Model Setup and Sensitivity Tests}

DSSAT and APSIM models were used to test the effects of climate change on crop production (McCown et al. 1996; Jones et al. 2003; Hoogenboom et al. 2010; Holzworth et al. 2015). Both DSSAT and APSIM are models that have been developed to simulate biophysical processes in crop farming systems in relation to economic and ecological outcomes of management practices in current or future farming systems (Hoogenboom et al. 2010; Holzworth et al. 2015; Steduto et al. 2009). For Nkayi the models have been calibrated (Masikati et al. 2014, 2015) and can be used with confidence in conducting ex-ante climate impact assessments on crop production systems.

For this study we assess the impacts of single climate factors $\left(\mathrm{CO}_{2}\right.$, temperature and rainfall) at varying levels (Table 5.1) and also the combined effects on maize and groundnut. Model simulations were done on three soil types which differed in soil physical and chemical characteristics (Table 5.2): poor, average and better soils representing about $29 \%, 59 \%$ and $12 \%$ of farms in the district, respectively. Current farmer management practices were used and these are defined in Table 5.3. Outputs from the models, which were considered for the current analyses, include grain and stover crop yields. Planting was set to be done automatically after the model detected that the set soil moisture conditions were met. For this study the sowing window was set between 1 November and 31 December, and planting was done when at least $15 \mathrm{~mm}$ of rain was received in three consecutive days.

\subsection{Results}

\subsubsection{Maize Response to $\mathrm{CO}_{2}$, Temperature, Rainfall and Fertilizer}

Maize sensitivity to $\mathrm{CO}_{2}$ was evaluated at different concentrations with $60 \mathrm{~kg} \mathrm{~N} / \mathrm{ha}$ and without nitrogen fertilizer. Without fertilizer, only the APSIM model simulates slight yield increases in response to increasing $\mathrm{CO}_{2}$ concentrations on better soils. However, when fertilizer is added both models simulate increases of maize yields with increasing $\mathrm{CO}_{2}$ across all soil types. Maize sensitivity to $\mathrm{CO}_{2}$ levels differed between the two models and across soil types (Fig. 5.2). Both maize grain and stover show incremental yields up to the maximum level evaluated here, 720 parts per million (ppm), which is more than double the current $\mathrm{CO}_{2}$ levels. 


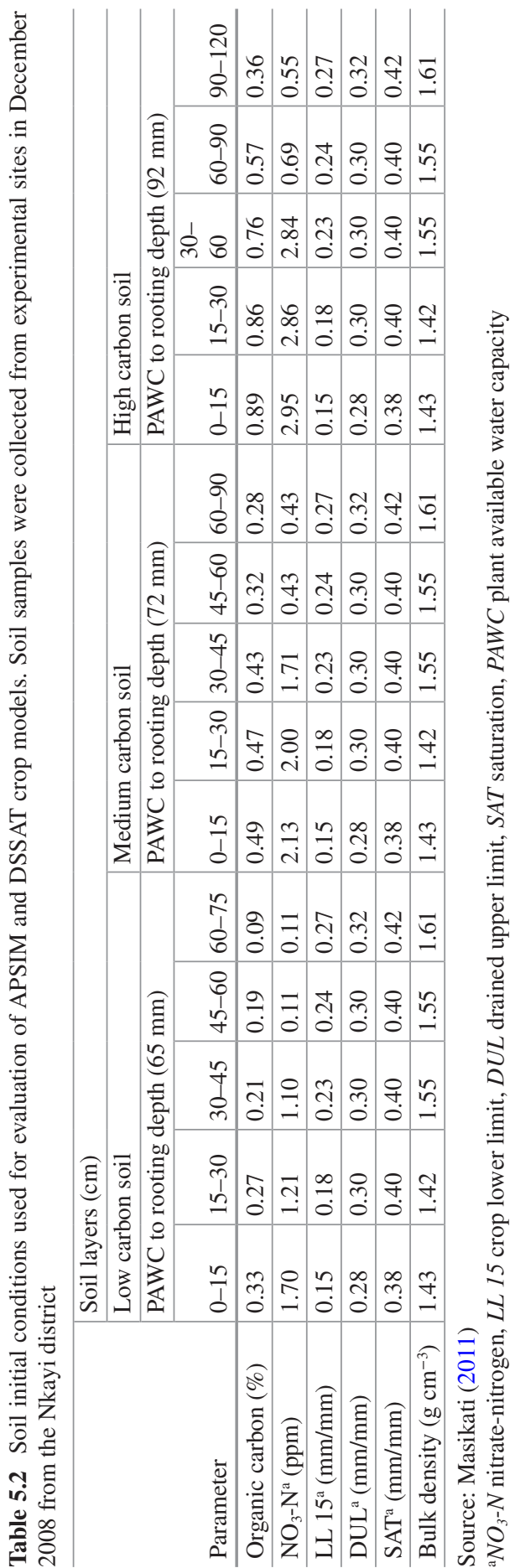


Table 5.3 Treatments used to assess the sensitivity of maize and groundnuts crops to different climate factors in Nkayi, Zimbabwe

\begin{tabular}{l|l}
\hline Crop & Treatment \\
\hline Maize & $\begin{array}{l}\text { Maize production under farmer practice (low-input system), average fertilizer } \\
\text { application: } 3 \mathrm{~kg} / \mathrm{ha}^{\mathrm{a}} \text { and average manure application: } 300 \mathrm{~kg} / \mathrm{ha} \mathrm{a}^{\mathrm{a}}\end{array}$ \\
\hline Groundnuts & $\begin{array}{l}\text { Groundnut production under farmer practice, use of low yielding recycled seed } \\
\text { with no fertilizer }\end{array}$ \\
\hline
\end{tabular}

aCRISAT (2008) and Masikati (2011)

In response to temperature the two models show divergent results on both maize grain and stover on poor soil. The APSIM model showed a slight increase for grain yields and a decrease for stover yields, however, the DSSAT model showed the opposite. Temperature increase of up to $2{ }^{\circ} \mathrm{C}$ would see a slight decrease of grain yields on poor soils, while the same temperature increase would substantially reduce grain yields on average and better soils with higher impact on the latter. Both models show almost no effects of temperature increases on maize stover across soil types.

In response to rainfall, a $25 \%$ reduction in rainfall, show yield reductions across all soil types, however impacts are higher on average and better soils. For example at $25 \%$ rainfall reduction yield losses on poor soils simulated by the APSIM model are $68 \mathrm{~kg} / \mathrm{ha}$, while on the average and better soils are 138 and $487 \mathrm{~kg} / \mathrm{ha}$, respectively. Simulated average grain yields for current rainfall are 434, 759 and $2110 \mathrm{~kg}$ / ha for poor, average and better soils, respectively. Conversely rainfall that was higher than the defined baseline was not beneficial to maize grown on poor soils. On better soils, maize yield increases were simulated only up to about $25 \%$ rainfall increases but after that there is a yield plateau.

On all soil types maize yields show positive response to increases in fertilizer application rates. Maize yields reach a plateau at about $60-70 \mathrm{~kg} \mathrm{~N} / \mathrm{ha}$ for all soil types, however, from $30 \mathrm{~kg} \mathrm{~N} / \mathrm{ha}$, the rate of yield increases on better soils is low compared to the other two soil types. Although increases are simulated across soils with increasing rates of fertilizer higher yield gains were simulated for poor than the other two soils at application rate of $30 \mathrm{~kg}$ N/ha. Grain yields gains with application of $30 \mathrm{~kg} \mathrm{~N} / \mathrm{ha}$ from base yields simulated by the APSIM model were 1314, 1190 and $466 \mathrm{~kg} / \mathrm{ha}$ for poor, average and better soils, respectively. The average base yields were 434, 759 and $2110 \mathrm{~kg} / \mathrm{ha}$. Above $60 \mathrm{~kg} \mathrm{~N} / \mathrm{ha}$, there is a yield plateau, meaning that the water environment at Nkayi becomes the limiting factor to achieving higher average yield.

\subsubsection{Groundnuts Response to $\mathrm{CO}_{2}$, Temperature, Rainfall and Fertilizer}

Groundnuts show high response to $\mathrm{CO}_{2}$ concentrations on all soil types (Fig. 5.3). The two models show similar trends although yields from the APSIM model are higher than those simulated by the DSSAT model. Both grain and stover yields 


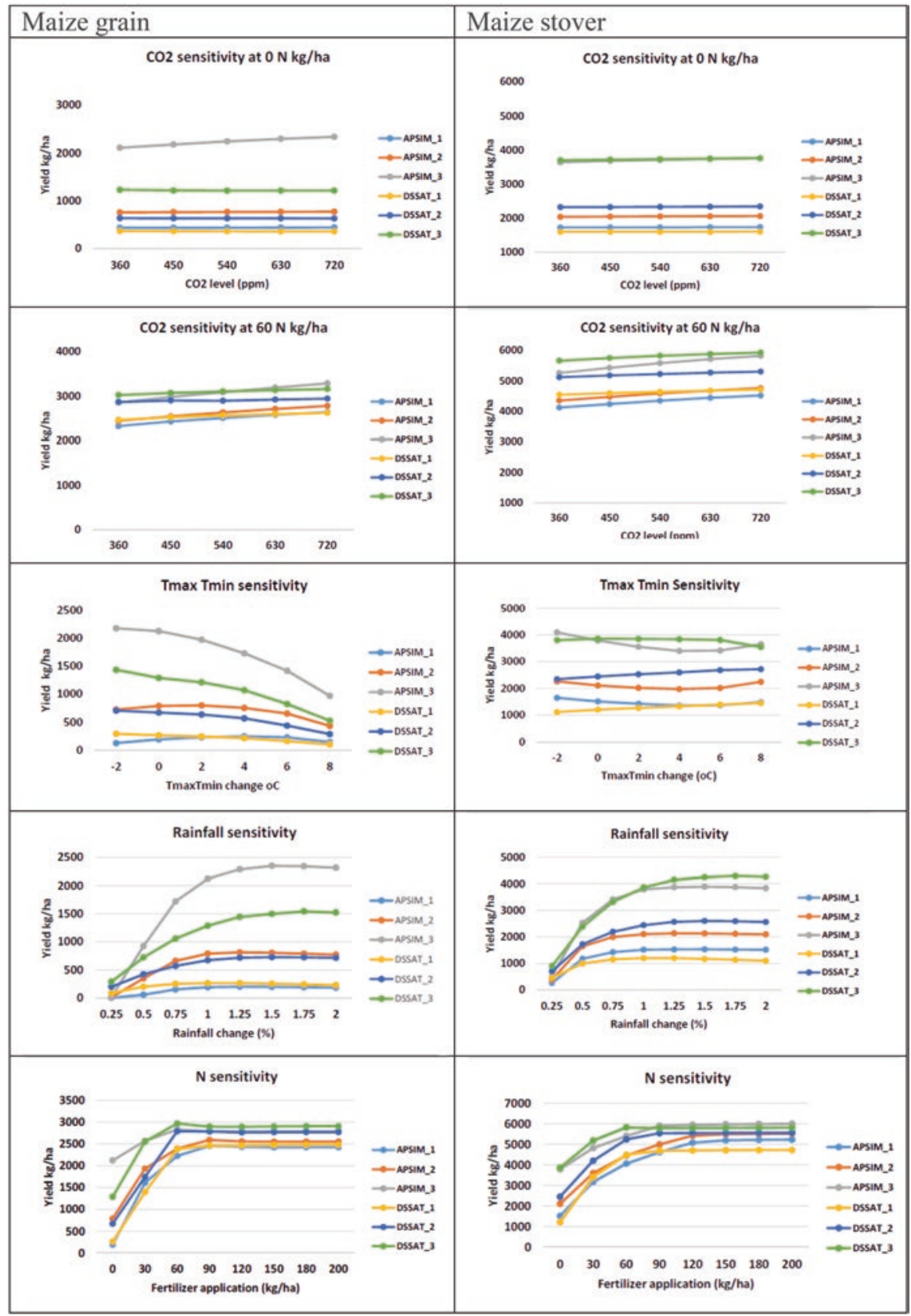

Fig. 5.2 Sensitivity of maize grain and stover to temperature, $\mathrm{CO}_{2}$, rainfall change and fertilizer application rates on different soil types, in Nkayi Zimbabwe. APSIM_1, APSIM_2 and APSIM_3 show simulations by the APSIM model for the three soil types: $1=$ poor; $2=$ average; $3=$ better. The same applies for the DSSAT model 


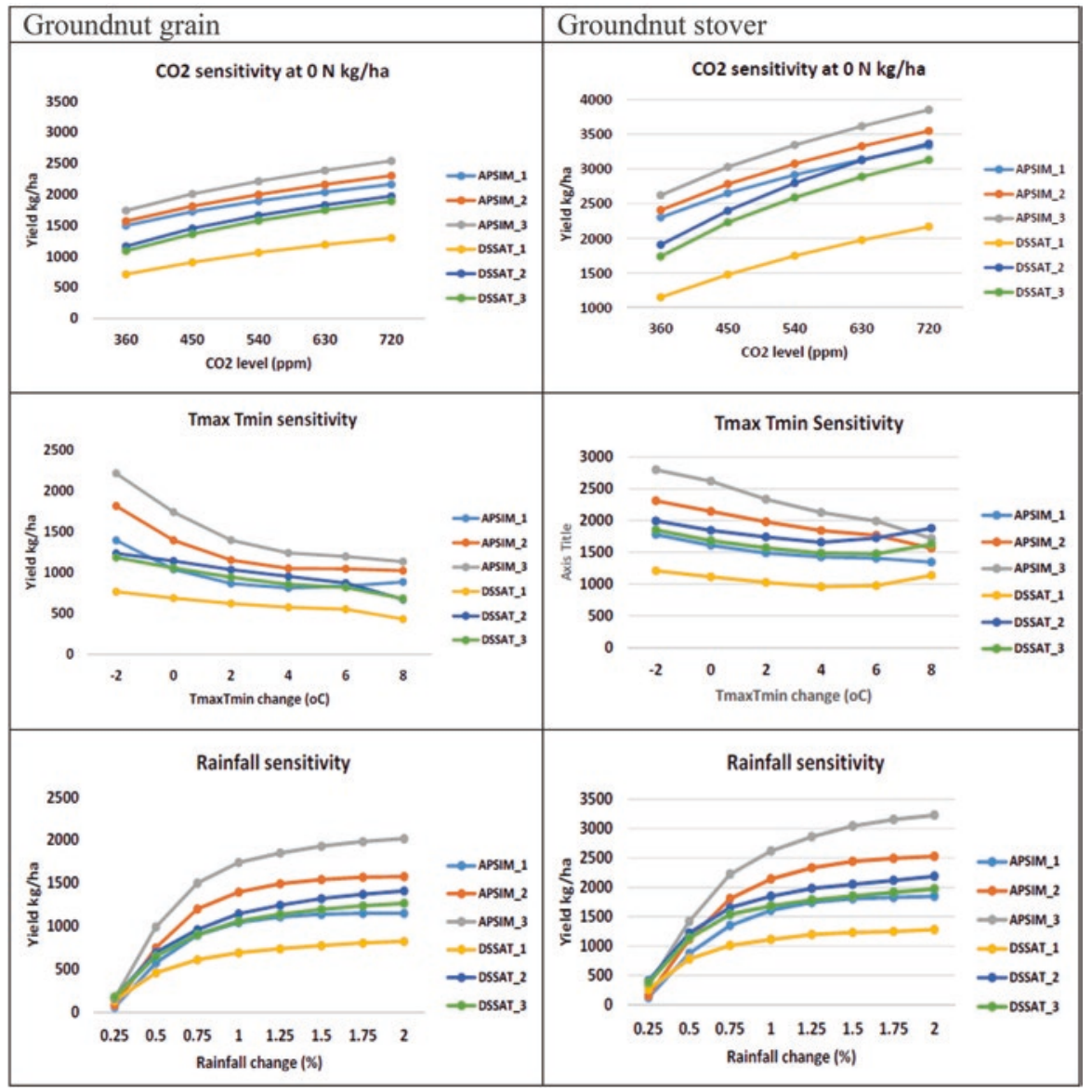

Fig. 5.3 Sensitivity of groundnut grain and stover to temperature, $\mathrm{CO}_{2}$ and rainfall change on different soil types, in Nkayi Zimbabwe. APSIM_1, APSIM_2 and APSIM_3 show simulations by the APSIM model for the three soil types: $1=$ poor; $2=$ average; $3=$ better. The same applies for the DSSAT model

increase up to the highest $\mathrm{CO}_{2}$ level evaluated here. The APSIM model simulated higher increases on the better soils while the DSSAT model simulated similarly large increases on the average soil.

In response to temperature changes, both models show negative effects of increased temperature and positive effects of decreased temperatures. Higher yield reductions were simulated for better soils than for the other two soils types. Both models show high yield reductions with temperature increases of about $2{ }^{\circ} \mathrm{C}$, however at higher temperature increases, for example at $+6^{\circ} \mathrm{C}$, the DSSAT model simulates slight stover yield increases across all soil types. 
Reduction in rainfall by about $50 \%$ shows substantial reductions in both grain and stover yields. Both stover and grain yields continue to increase as rainfall increases, however, the increases are very small.

\subsubsection{Combined Effects of Climate Factors on Maize}

We evaluated the combined effects of climate elements on maize grain and stover yield. Hot/wet and hot/dry climate scenarios for both RCP4.5 and 8.5 were used. The effects were simulated by both the APSIM and DSSAT model on three soil types. The two models show divergent effects of combined climate elements on both maize grain and stover. The APSIM model shows more stover yield reductions while the DSSAT model shows more grain reductions across soils and climate scenarios. Yield reductions are more pronounced on better soils than on the other two soil types, while the hot/wet climate scenario shows more positive effects than the hot/dry scenario. Climate effects are more distinct for grain than for stover and this is more pronounced for RCP8.5 than RCP4.5. Generally, the hot/dry conditions show substantial reductions with probability of 35,40 and $70 \%$ of getting reduced grain yields as simulated by the APSIM model while the DSSAT model shows 85 , 75 and $85 \%$ on poor, average and better soils respectively under RCP4.5 hot/dry conditions. Generally, maize production will decrease under future climate scenarios though the degree of impact differs among soil types.

\subsubsection{Combined Effects of Climate Factors on Groundnuts}

In contrast to maize, groundnuts mostly showed positive effects with yield increases of more than $50 \%$ for stover in some instances. The APSIM model generally simulated positive grain yields under RCP4.5 and reductions at a probability of 19, 30 and $50 \%$ for poor, average and better soils, respectively under RCP8.5 hot/dry conditions. Stover yields showed positive yield increases for both RCP4.5 and RCP8.5 under hot/wet conditions. However, reductions were simulated for hot/dry conditions mainly for RCP8.5. The DSSAT model shows more negative effects on grain yields than stover yields across soil types and climate scenarios. Grain yield reductions are more pronounced for average and better soils under hot/dry climate scenarios for both RCP4.5 and 8.5. Stover yields on average soil are mostly affected showing about $40 \%$ probability of getting negative yields. Although groundnuts seem to be benefitting on average, however there are years when yield changes are negative. 


\subsection{Discussion}

\subsubsection{Maize and Groundnut Response to $\mathrm{CO}_{2}$, Temperature, Rainfall and Fertilizer}

Temperature increases in areas such as Zimbabwe where crops are grown near thresholds can be detrimental to rain-fed crop production. Increased temperatures can negatively affect crop yields by accelerating crop phonological stages hence less time for biomass accumulation (Asseng et al. 2015). In this study, increased temperatures show negative effects on both maize and groundnut yields across soil types with higher yield reductions simulated on the better soils. Although simulated yield reductions were higher on better soils, average grain and stover yields were always higher than those for poor soils.

Responses to $\mathrm{CO}_{2}$ can vary by crop species (Asseng et al. 2015). In our study, maize showed minimal increases of about 5\% for both the APSIM and DSSAT model with fertilizer, however, groundnuts showed average increases of about $23 \%$. Asseng et al. (2015) reported that C4 (e.g., maize, sorghum, millet) and C3 (e.g., wheat, groundnuts, potatoes) plants when $\mathrm{CO}_{2}$ is increased to 500-550 (ppm), grain yield can be increased by $10-20 \%$ and by $<13 \%$ for $\mathrm{C} 3$ and $\mathrm{C} 4$, respectively. Responses to $\mathrm{CO}_{2}$ also depend on soil water and nutrient availability with highest responses being reported under soil water limiting conditions (Kang et al. 2002). However low soil fertility can reduce the possible positive effects of elevated $\mathrm{CO}_{2}$ on yields (Yang et al. 2006). This was also simulated in the current study where there were minimal to no benefits at all with increases in $\mathrm{CO}_{2}$ across all soil types when no fertilizer was added. However positive responses were simulated with application of $60 \mathrm{~kg} \mathrm{~N} / \mathrm{ha}$ with higher increases simulated on better soils. Both stover and grain yields increased as $\mathrm{CO}_{2}$ concentrations increased up to the $720 \mathrm{ppm}$ level. Increases of $\mathrm{CO}_{2}$ in the atmosphere is one of the most certain aspects of climate over the coming decades and leguminous crops such as groundnuts have the potential to benefit from this. Leguminous crops fix the atmospheric nitrogen, release high-quality organic matter in the soil and allow sequestration of carbon in soil. If used as feed (provided the quality is not affected), leguminous crops could reduce methane emissions from livestock. These multiple benefits provide both mitigation and adaptation benefits to farmers.

Rainfall variability can have both positive and negative impacts on agriculture depending on the environment. Reduced rainfall by about $25 \%$ can be detrimental to crop yields while increases by similar magnitude would not be as beneficial in low input systems and more importantly on poor soils. Rainfall distribution also plays an important role, as lack of rainfall at crop critical growth stages such as anthesis can substantially reduce grain yield.

Smallholder farming systems are low input systems with an average nitrogen application rate of $3 \mathrm{~kg} / \mathrm{ha}$ and zero fertilizer application for legumes such as groundnuts. General fertilizer recommendations for different soil types are up to $110,110-140$ and $140-180 \mathrm{~kg} \mathrm{~N} /$ ha for better, average and poor soils, respectively, 
which is beyond what most farmers can afford (FAO 2006; Vanlauwe and Giller 2006). However, in our current study both models simulate yield plateau at $60 \mathrm{~kg} \mathrm{~N} /$ ha for better soils and at around $70 \mathrm{~kg} \mathrm{~N} / \mathrm{ha}$ for poor soils. The biophysical and socio-economic situation needs to be considered for establishing recommendations and these should be location-specific and dynamic because soil changes depending on how it is managed.

\subsubsection{Combined Effects of Climate Factors on Maize and Groundnuts}

Temperatures are projected to increase in Nkayi district, however, rainfall is likely to change by $-15 \%$ to $+10 \%$. Average annual rainfall for Nkayi is about $650 \mathrm{~mm}$ per year and the projected reductions and increases can lead to 552 and $715 \mathrm{~mm}$ per year, respectively. Variability will be high especially under hot/dry conditions as shown by the variations in yields reductions (Figs. 5.4 and 5.5). Yield variability is higher for maize grain than stover while for groundnuts high variability is only simulated by the DSSAT model for both grain and stover. Increased temperature effects supersede the other factors and will be mostly detrimental to maize while high response to $\mathrm{CO}_{2}$ exhibited by groundnuts negate the negative effects of increased temperature. Increased temperature reduces crop yields by accelerating crop phonological stages, hence, reducing the time for biomass accumulation. Another adverse effect of high temperature is heat and/or water stress, which at the critical crop growth stages, such as anthesis or grain filling, also reduces crop yields. It will be important to assess which effect will be more prominent and this information could be used when developing adaptation strategies. Important is also to assess the particular times when crops are water stressed so that farmers can adjust water and nutrient management, planting and sowing dates, plant densities and cultivar choice. Climate-smart agricultural practices such as agroforestry that make use of water more efficiently and have the potential to induce microclimatic conditions can be recommended in areas affected by heat stress (Mbow et al. 2014).

\subsection{Implications for Development}

Crop models are important tools that can be used to understand disaggregated effects of climate elements on crop production. However, models do differ in the way they are constructed and in their responses to different effects of climatic factors on crop production. We used two crop models DSSAT and APSIM and both models generally agreed on the effects of different climatic factors on maize and groundnuts. It is only the magnitude of the effects that vary, for example, reductions on maize grain yields are more pronounced in the APSIM model while the DSSAT 


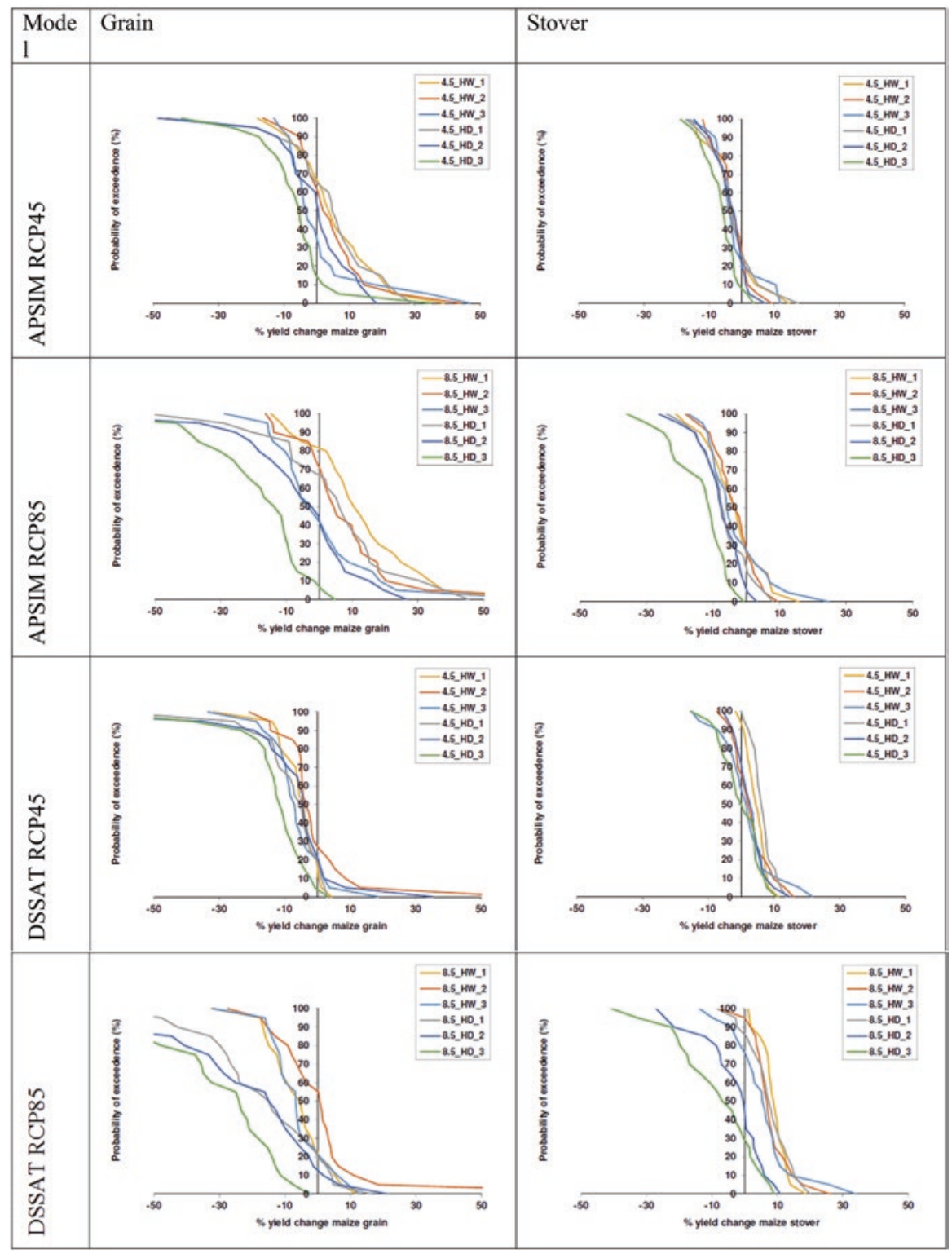

Fig. 5.4 Probability of exceedance for maize grain and stover yield reductions simulated by APSIM and DSSAT models for RCP4.5 and 8.5 for hot/wet and hot/dry climate scenarios. 8.5 HW_1, 8.5_HW_2, 8.5_HW_3 = RCP8.5, hot/wet for poor, average and better soils, respectively. HD represent hot/dry; HW represent hot/wet

model shows more pronounced reduction of maize stover yields. Both models show yield benefits under elevated $\mathrm{CO}_{2}$ concentration for groundnuts negating the effects of increased temperatures when evaluating the combined effects of the climatic factors. However, yield increases for both groundnut grain and stover are more 


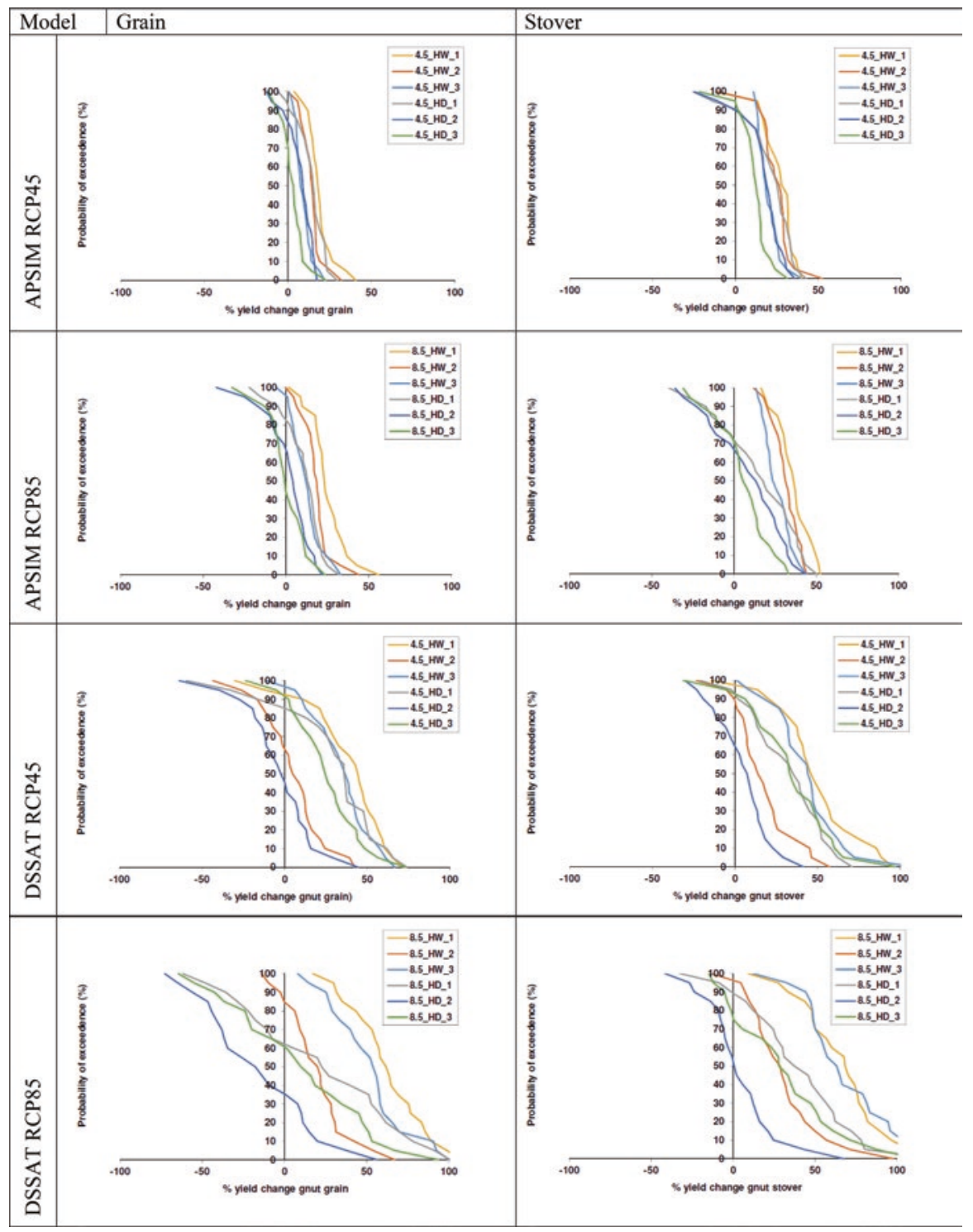

Fig. 5.5 Probability of exceedance for groundnut grain and stover yield reductions simulated by APSIM and DSSAT models for RCP4.5 and 8.5 for hot/wet and hot/dry climate scenarios. $8.5_{-}$ HW_1, 8.5_HW_2, 8.5_HW_3 = RCP8.5, hot/wet for poor, average and better soils, respectively. $\mathrm{HD}$ represents hot/dry, HW represent hot/wet

pronounced in the DSSAT model than in the APSIM model. Soils play an important role in determining outputs of crop-climate interactions; they can buffer or aggravate climatic impacts. Better soils exhibited higher responses to positive influences such as increased rainfall and $\mathrm{CO}_{2}$ concentrations compared to poor soils. Better soils would be more important in future farming systems. 
Acknowledgements In this paper we use the Agricultural Model Intercomperison Project approach (AgMIP, www.agmip.org), using the case study of the crop-livestock Intensification Project (CLIP). UKAID and USDA funded the research. We are grateful to communities in Nkayi district, Matabeleland North and Zimbabwe national stakeholders for their contributions. The research contributes to CGIAR research program CCAFS.

\section{References}

Asseng S, Zhu Y, Wang E et al (2015) Crop modeling for climate change impact and adaptation. In: Crop physiology: applications for genetic improvement and agronomy, 2nd edn. Elsevier, London, Waltham, San Diego, pp 505-546. https://doi.org/10.1016/B978-0-12417104-6.00020-0

FAO (2006) Fertilizer use by crop in Zimbabwe. Land and plant nutrition management service. Land and water development division. Food and Agriculture Organization of the United Nations, Rome

Folberth C, Yang H, Gaiser T et al (2013) Modeling maize yield responses to improvement in nutrient, water and cultivar inputs in sub-Saharan Africa. Agric Syst 119:22-34

Folberth C, Skalsky R, Moltchanova E et al (2016) Uncertainty in soil data can outweigh climate impact signals in global crop yield simulations. Nat Commun 7:11872. https://doi.org/10.1038/ ncomms 11872

GGCA (2012) Gender climate change and food security. Policy brief. Global Gender and Climate Alliance, United Nations Development Programme, New York

Holzworth D, Huth NI, Fainges J et al (2015) APSIM next generation: the final frontier. In: Weber T, McPhee MJ, Anderssen RS (eds) MODSIM2015, 21st international congress on modelling and simulation. Modelling and Simulation Society of Australia and New Zealand, December 2015, p 490-496. Available from: www.mssanz.org.au/modsim2015/B4/walmsley.pdf

Hoogenboom G, Jones JW, Wilkens PW et al (2010) Decision support system for agrotechnology transfer (DSSAT) version 4.5 [CD-ROM]. University of Hawaii, Honolulu

ICRISAT (2008) Crop-livestock water productivity project household survey (Nkayi District, Zimbabwe). International Crops Research Institute for the Semi-Arid Tropics, Harare

Ioras F, Bandara I, Kemp C (2014) Introduction to climate change and land degradation. In: Arraiza MP, Santamarta JC, Ioras F et al (eds) Climate change and restoration of degraded land. Colegio de Ingenieros de Montes, Madrid, pp 15-48

Jones JW, Hoogenboom G, Porter CH et al (2003) DSSAT cropping system model. Eur J Agron 18:235-265

Kang SZ, Zhang FC, Hu XT et al (2002) Benefits of $\mathrm{CO}_{2}$ enrichment on crop plants are modified by soil water. Plant Soil 238(1):69-77. https://doi.org/10.1023/A:1014244413067

Lisk F (2009) The current climate change situation in Africa. In: Besada H, Sewankambo NK (eds) Climate change in Africa: adaptation, mitigation and governance challenge. The Centre for International Governance Innovation, Waterloo, pp 8-15

Makinen H, Kaseva J, Virkajarvi P et al (2017) Shifts in soil-climate combination deserve attention. Agric For Meteorol 234-235:236-246

Masikati P (2011) Improving the water productivity of integrated crop-livestock systems in the semi-arid tropics of Zimbabwe: ex-ante analysis using simulation modeling. Dissertation, Centre for Development Research (ZEF), University of Bonn

Masikati P, Manschadi A, van Rooyen A et al (2014) Maize-mucuna rotation: an alternative technology to improve water productivity in smallholder farming systems. Agric Syst 123:62-70

Masikati P, Homann-KeeTui S, Descheemaeker K et al (2015) Crop-livestock intensification in the face of climate change: exploring opportunities to reduce risk and increase resilience in Southern Africa using an integrated multi-modeling approach. In: Rosenzweig C, Hillel D (eds) Handbook of climate change and agroecosystems: the Agricultural Model Intercomparison and Improvement Project (AgMIP) integrated crop and economic assessments, ICP Series on 
Climate Change Impacts, Adaptation, and Mitigation, vol 3. Imperial College Press, London, pp 90-112

Mbow C, Smith P, Skole D et al (2014) Achieving mitigation to climate change through sustainable agroforestry practices in Africa. Curr Opin Environ Sustain 6:8-14

McCown RL, Hammer GL, Hargreaves JNG et al (1996) APSIM: a novel software system for model development, model testing, and simulation in agricultural research. Agric Syst 50:255-271

Moyo M (2001) Representative soil profiles of ICRISAT research sites Chemistry and Soil Research Institute, Soils Report No A666. Agriculture Research Extensions (AREX), Harare, p 97

Nyamangara J, Gotosa J, Mpofu SE (2001) Cattle manure effects on structural Stability and water retention capacity of a granitic sandy soil in Zimbabwe. Soil Tillage Res 62(3-4):157-162

Perez C, Jones EM, Kristjanson P et al (2015) How resilient are farming households and communities to a changing climate in Africa? A gender-based perspective. Glob Environ Chang 34:95-107

Piikki K, Winowiecki L, Vagen TG et al (2015) The importance of soil fertility constraints in modeling sustainability under progressive climate change in Tanzania. Procedia Environ Sci 29:199-211

Ruane AC, McDermid SP (2017) Selection of a representative subset of global climate models that captures the profile of regional changes for integrated climate impacts assessment. Earth Perspect 4:1. https://doi.org/10.1186/s40322-017-0036-4

Ruane AC, Goldberg R, Chryssanthacopoulos J (2014) Climate forcing datasets for agricultural modeling: merged products for gap-filling and historical climate series estimation. Agric For Meteorol 200:233-248. https://doi.org/10.1016/j.agrformet.2014.09.016

Rurinda J, van Wijk MT, Mapfumo P et al (2015) Climate change and maize yield in southern Africa: what can farm management do? Glob Chang Biol 21(12):4588-4601

Steduto P, Hsiao TC, Raes D et al (2009) AquaCrop-the FAO crop model to simulate yield response to water: I. Concepts and underlying principles. Agron J 101(3):426-437

Tittonell P, Zingore S, van Wijk MT et al (2007) Nutrient use efficiencies and crop responses to N, $\mathrm{P}$ and manure applications in Zimbabwean soils: exploring management strategies across soil fertility gradients. Field Crop Res 100:348-368

UNCCD (2014) Land-based adaptation and resilience: powered by nature. 2nd edn 2014. Secretariat of the United Nations Convention to Combat Desertification. Secretariat of the United Nations Convention to Combat Desertification, Bonn. Available from: http://www.eldinitiative.org/fileadmin/pdf/Land_Based_Adaptation_ENG_Sall_web.pdf

Vanlauwe B, Giller KE (2006) Popular myths around soil fertility management in sub-Saharan Africa. Agric Ecosyst Environ 116:34-46

Vermeulen SJ, Aggarwal PK, Ainslie A et al (2012) Options for support to agriculture and food security under climate change. Environ Sci Policy 15:136-144

Yang L, Huang J, Yang $\mathrm{H}$ et al (2006) The impact of free-air $\mathrm{CO}_{2}$ enrichment (FACE) and $\mathrm{N}$ supply on yield formation of rice crops with large panicle. Field Crops Res 98:141-150

Zingore S, Tittonell P, Corbeels M et al (2011) Nutr Cycl Agroecosyst 90:87-103

Open Access This chapter is licensed under the terms of the Creative Commons Attribution 4.0 International License (http://creativecommons.org/licenses/by/4.0/), which permits use, sharing, adaptation, distribution and reproduction in any medium or format, as long as you give appropriate credit to the original author(s) and the source, provide a link to the Creative Commons license and indicate if changes were made.

The images or other third party material in this chapter are included in the chapter's Creative Commons license, unless indicated otherwise in a credit line to the material. If material is not included in the chapter's Creative Commons license and your intended use is not permitted by statutory regulation or exceeds the permitted use, you will need to obtain permission directly from the copyright holder. 